\title{
Author Correction: When Twitter Fingers Turn to Trigger Fingers: a Qualitative Study of Social Media-Related Gang Violence
}

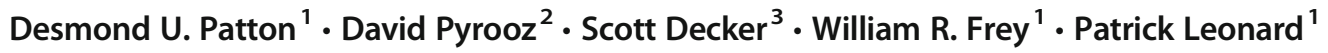

Published online: 27 April 2019

(C) Springer Nature Switzerland AG 2019

\section{Author Correction: International Journal of Bullying Prevention https://doi.org/10.1007/s42380-019-00014-w}

The original version of this article unfortunately contained a mistake. The name of the second author was spelled incorrectly. The correct name of the second author is "David Pyrooz."

The author apologizes for this oversight and for any confusion it may have caused.

The original article has been corrected.

The online version of the original article can be found at https://doi.org/ 10.1007/s42380-019-00014-w

Desmond U. Patton

dp2787@ columbia.edu

1 Columbia University, 1255 Amsterdam Ave., New York, NY 10027 , USA

2 University of Colorado, UCB 327 Ketchum 195, Boulder, CO 80309, USA

3 Arizona State University, 411 N. Central Ave., Phoenix, AZ 85004, USA 